\begin{tabular}{|l|}
\hline ARASTTIRMA \\
MAKALESI \\
\hline
\end{tabular}

Teslime Ayaz ${ }^{1}$

Özlem Bilir ${ }^{2}$

Gökhan Ersunan ${ }^{2}$

Osman Zikrullah Şahin ${ }^{1}$

Özcan Yavași ${ }^{2}$

Halil Rakıcı ${ }^{1}$

\begin{abstract}
${ }^{1}$ Recep Tayyip Erdoğan Üniversitesi Tıp Fakültesi İç Hastalıkları AD. Rize

${ }^{2}$ Recep Tayyip Erdoğan Üniversitesi Tıp Fakültesi Acil Tip AD. Rize
\end{abstract}

Yazısma Adresi

Yrd. Doç. Dr. Teslime Ayaz Recep Tayyip Erdoğan

Üniversitesi Eğitim ve Araştırma

Hastanesi İ̧ Hastalıkları AD,

53100-Rize

Telefon: 464-2130491

Faks: +90 464-2170364

Email:drthess@hotmail.com

Geliș Tarihi: 14.01.2014

Kabul Tarihi: 22.04.2014

\section{İntihar Amaçlı İlaç Zehirlenmelerinin Değerlendirilmesi}

ÖZET

Amaç: Zehirlenmeler, intihar amaçlı ya da farkında olmadan yüksek dozda ilaç veya madde alımı sonucu meydana gelmektedir. Çalışmamızda, dahili yoğun bakım ünitesi ve dahiliye kliniğinde yatırılarak takip ve tedavi edilen zehirlenme vakalarının; demografik özellikleri, zehirlenme nedeni ve prognozu açısından retrospektif olarak değerlendirmeyi ve ülkemizin zehirlenme verilerine katkıda bulunmayı amaçladık.

Yöntem: Kasım 2008-Kasım 2013 tarihleri arasında Recep Tayyip Erdoğan Üniversitesi Eğitim ve Araştırma Hastanesi Acil Servisine, intihar amaçlı ilaç alma nedeniyle başvuran 15 yaş ve üzeri hastaların dosyaları geriye dönük olarak incelendi.

Bulgular: Çalışmaya dahil edilen 127 hastanın \%75,6'sı (96) bayan idi. Ortalama yaş $25 \pm 9,6$ y1l olup $\% 37$ 'sini 20 yaş altı hastalar oluşturmaktaydı. Etken farmakolojik ajanın en çok \%28,3 ile anti-depresan ilaçların olduğu görülmüştür. Alınan ilaç miktarına bakıldığında \%22 ile 15-20 adet arasındadır. Olguların \%58,3'ü 1-2 saat aralığında ilaç alımından sonra hastaneye başvurmuştur. Hastalar ortalama 1.88 gün hastanede yatırılarak takip ve tedavi edilmiştir. Psikiyatri konsültasyon sonuçlarını değerlendirdiğimizde, olguların \%50,4'ü depresyon tanısı almışırı.

Sonuç: İntihar amaçlı ilaç alımlarında genç yaş grubu ve kadınlar risk altındaki gruptur. Özellikle depresif psikiyatrik bozukluğu olan kişilerde intihar girişimi daha sık görülmektedir. İlaç alımlarından sonra, kısa sürede hastaneye başvuru hastanede kalış süresini ve mortaliteyi azaltmaktadır.

Anahtar Kelimeler: İntihar, İlaç, Zehirlenme.

\section{Evaluation of Drug Intoxications Due To Suicides}

\begin{abstract}
Objective: The intoxications occur via taking high doses of drugs or substances for the purpose of suicide or unconsciously. In this retrospective study, we aimed to explore the causes of intoxications and to evaluate the demographic and clinical features and the prognosis of patients who were followed and treated for intoxications in our intensive care unit or internal medicine clinic and secondly we aimed to add information for the data of intoxications in our country.

Methods: All patients over 15 years old who admitted to Emergency Unit of Recep Tayyip Erdoğan University Teaching and Research Hospital for the intoxications because of suicide, between November 2008 and November 2013 included in this study.

Results: 127 patients were enrolled in the current study and 75,6\% (96) of the patients were female. Mean age of the patients was 25,04 $\pm 9,61$ years and $37 \%$ of the patients were under 20 years old. The antidepressant agents were the most frequent pharmacologic agent $(28,3 \%)$ as the cause of intoxications. The number of drugs taken for the intoxication was 15-20 in $22 \%$ of the patients. $58,3 \%$ of the patients admitted to the hospital after $1-2$ hours taking the drug. The patients were followed and treated for meanly 1.88 days in the hospital. When we evaluated the results of psychiatry consultation reports, we found that $50,4 \%$ of the patients were diagnosed with depression.

Conclusion: The young and female patients are on the risk of drug abuse for the aim of suicide. Particularly, suicides are observed more frequently in the patients with depression. Admission to the hospital in a short time after taking the drugs reduces the time of stay in hospital and mortality.

Keywords: Suicide, Drug, Intoxication.
\end{abstract}

Konuralp Tıp Dergisi e-ISSN1309-3878

konuralptipdergi@duzce.edu.tr konuralpgeneltip@gmail.com www.konuralptipdergi.duzce.edu.tr 


\section{GíRiş}

Zehirlenmeler, ilk çağlardan günümüze kadar önemli tıbbi ve toplumsal bir problem olma özelliğini korumaktadır. Genellikle intihar amaçlı ya da farkında olmadan yüksek dozda ilaç veya madde alımı sonucu meydana gelmektedir. Alınan maddeye ve hastaneye başvuru süresine bağlı olarak ciddi sonuçlar ortaya çıkabilmektedir. Özellikle intihar amaciyla alınan pestisitlerde mortalite artmakta ve dünyada y1lda 300.000 kişinin bu nedenle öldüğü tahmin edilmektedir $(1,2)$. Ülkemizde az sayıda yapılan epidemiyolojik çalışmaların sonuçlarına göre yıllık zehirlenme insidansı \% 0,8-5 olarak saptanmıştır $(1,3)$.

Kişinin istemli olarak yaşamına son vermesi olarak tanımlanan intihar, tüm zehirlenme vakalarının yaklaşık \%95'ini oluşturmaktadır ve kadın cinsiyette daha sık görülmektedir. İntiharlar psikiyatride en önemli ölüm sebeplerinden biridir. Zehirlenmeler sıklık sırasına göre; ilaçlar, keyif verici maddeler, ev- endüstriyel ve tarımsal kaynaklı toksik maddelerle oluşmaktadır (4-6).

İntihar riski ile psikiyatrik hastalıklar arasındaki ilişki incelendiğinde; afektif bozukluğu olanlarda \%15, alkol ve madde bağımlılarında \%15, Şizofrenilerde $\% 10$ ve kişilik bozukluğu bulunanlarda $\% 10$ oranında intihar olgularına rastlanılmıştır $(7,8)$. Nöroz grubunda ise en sık panik bozukluğu olanlarda görülürken, majör depresyonu olup yetersiz antidepresan kullanımı olan hastalarda intihar açısından ciddi risk altında oldukları bildirilmiştir (9).

Biz bu çalışmamızda, hastanemiz dahili yoğun bakım ünitesi ile dahiliye kliniğinde yatırılarak takip ve tedavi edilen zehirlenme vakalar1; demografik özellikleri, zehirlenme nedenleri ve prognozları açısından retrospektif olarak değerlendirilerek ülkemizin zehirlenme verilerine katkıda bulunmayı amaçladık.

MATERYAL VE METOT

Kasım 2008-Kasım 2013 tarihleri arasında Recep Tayyip Erdoğan Üniversitesi Eğitim ve Araştırma Hastanesi Acil Servisine, intihar amaçlı ilaç alma nedeniyle başvuran 15 yaş ve üzeri hastaların dosyaları geriye dönük olarak incelendi. İlk müdahaleleri yapıldıktan sonra Dahili Yoğun Bakım Ünitesi veya Dahiliye Kliniğinde yatırılarak takip ve tedavi edilen vakaların demografik özellikleri, aldıkları farmakolojik ajanlar ve ilaç miktarları kaydedildi. Psikiyatri konsültasyon sonuçları, varsa daha önceki tedavileri, olmuşsa daha önceki intihar girişimleri incelendi.

Elde edilen veriler SPSS Yazılım (Sürüm 17, SPSS, Inc, Chicago, IL, ABD) kullanılarak analiz edildi. Sonuçlar ortalama \pm standart sapma olarak ifade edildi. Mann-Whitney U testi sürekli değişkenler karşılaştırmak için kullanıldı ve ki-kare testi, kategorik değişkenlerin karşılaştırılmasında kullanıldı. $\mathrm{p}<0.05$ değeri istatistiksel olarak anlamlı kabul edildi.

\section{BULGULAR}

Çalışmaya toplam 127 hasta dahil edildi. Olguların \%75,6's1 (n=96) kadındı. Hastaların ortalama yaşı 25,04 $\pm 9,61$ (min:15-max:55) olup, \%37'sini 20 yaş altı hastalar oluşturmaktaydı (Şekil 1). Etken farmakolojik ajanın en çok $\% 28,3$ ile antidepresan ilaçlar olduğu görüldü (Tablo 1). Alınan ilaç miktarına bakıldığında \%22 ile 15-20 adet arasındaydı (Şekil 2). Hastaların anamnezi incelendiğinde, sadece iki tanesi dışında kendi kullandığ 1 ilaçları aldığ 1 tespit edildi.

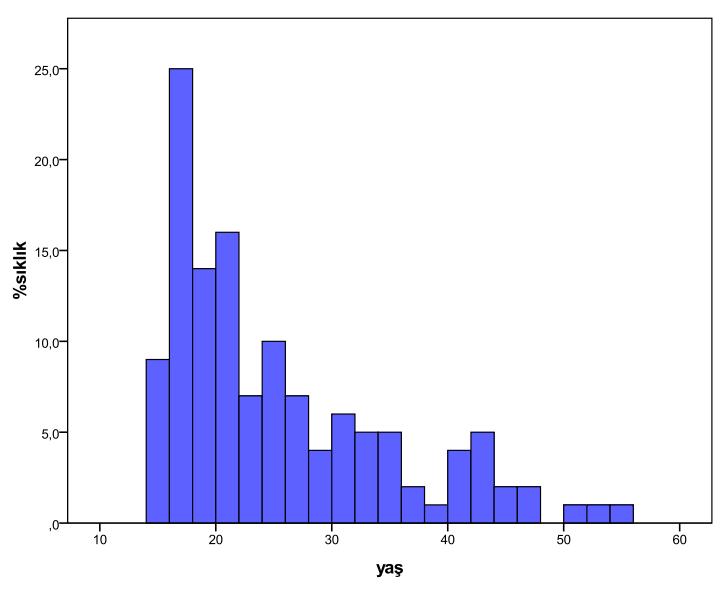

Şekil 1. Olguların yaş gruplarına göre dağılımı

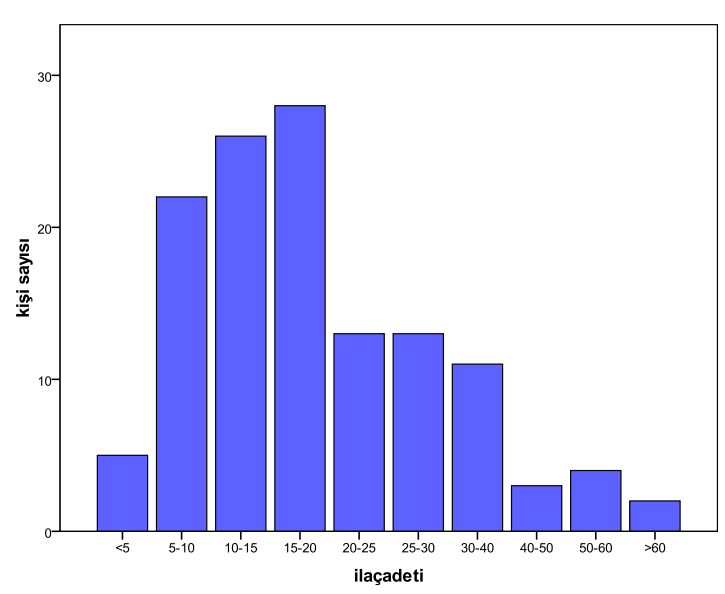

Şekil 2. Olguların aldığı ilaç sayısının dağılımı.

Hastaların ilaç alımından sonra hastaneye başvurma sürelerine baktığımızda, olguların \%58,3'ü 1-2 saat aralığında, \%37 si ilk bir saatte, sadece 1 hasta 8 saat sonra acil servise gelmişti. Acil serviste gastrik lavaj ve aktif kömür uygulamas1 yapıldıktan sonra hastaların \%26's1 Dahili Yoğun Bakım Ünitesinde takibe alınmıştı. Dahili Yoğun Bakım Ünitesinde takip edilen hastaların hiçbirinde entübasyon gerektirecek bir komplikasyon ortaya çıkmamıştı. Hastanede kalış süreleri ortalama 1.88 gün olup, $\% 41$ 'i bir gün hastanede yatırılarak takip ve tedavi edilmişlerdi. 
Hasta grubumuzu intihar amaçlı ilaç zehirlenmeleri oluşturduğu için tüm hastaların yatışta ve/veya taburculuk öncesi psikiyatri konsültasyonları yapılmıştı. Konsültasyon sonuçlarını değerlendirdiğimizde, olguların \%50,4'ünde depresyon ve \%28,3'üne anksiyete tanısı konulmuştu (Tablo 2). Psikiyatrik değerlendirme sonrasında depresyon tanısı alan hastaların \%38,1'inin öncesine ait depresyon tanıs1 mevcuttu. Hastaların taburculuk hallerine bakıldığında olguların \%68,5'inin ilaç tedavisi düzenlenerek önerilerle evine gönderildiği, \%31,5'inde intihar düşüncesinin devam etmesi sebebiyle yataklı psikiyatri kliniğine yönlendirilmiştir. Çalışmaya dahil edilen hastaların hiçbirinde zehirlenme nedeniyle ölüm olmadı.

Tablo 1. Etken farmakolojik ajanlar

\begin{tabular}{lll}
\hline ALINAN ILAÇ & n & \% \\
\hline Antidepresan & 36 & 28,3 \\
Antidepresan+anksiyolitik & 2 & 1,6 \\
Anksiyolitik & 12 & 9,4 \\
Antipsikotik & 9 & 7,1 \\
Parasetamol & 25 & 19,7 \\
Parasetamol+psodoefedrin & 2 & 1,6 \\
Parasetamol+antidepresan & 7 & 5,5 \\
Parasetamol +Antiülser & 3 & 2,4 \\
Parasetamol+NSAİD* & 5 & 3,9 \\
Parasetamol+antibiyotik & 9 & 7,1 \\
Antibiyotik & 3 & 2,3 \\
NSAİ** & 7 & 5,5 \\
Antihipertansif & 5 & 3,9 \\
Antidiyabetik & 1 & 0,8 \\
Antiülser & 4 & 3,1 \\
\hline
\end{tabular}

*NSAIID: Nonstreoid Antiinflamatuvar Drug

Tablo 2. Psikiyatri konsültasyon tanıları

\begin{tabular}{lll}
\hline PSİKIYYATRİK TANI & n & \% \\
\hline Depresyon & 64 & 50,4 \\
Anksiyete & 36 & 28,3 \\
Şizofreni & 6 & 4,7 \\
Depresyon + Anksiyete & 3 & 2,4 \\
İmpulsif Bozukluk & 5 & 3,9 \\
Bipolar Bozukluk & 3 & 2,4 \\
Davranış Bozukluğu & 3 & 2,4 \\
Psikosomatik Bozukluk & 4 & 3,2 \\
Madde Bağımlıı̆̆ı & 2 & 1,6 \\
Kişilik Bozukluğu & 1 & 0,8 \\
\hline
\end{tabular}

Hastaların yaş dağılımı ile cinsiyet arasında bir karşılaştırma yapıldığında kadınların intihara daha fazla meyilli olduğu tespit edilmiştir ve istatistiksel olarak anlamlı fark bulunmuştur $(p=0,009)$. Hastaneye başvuru süreleri açısından kadın ve erkeler arasında anlamlı fark bulunamamıştır $\quad(p=0.079)$. Hastanede kalış sürelerine bakıldığında erkekler ortalama $2.29 \pm 0,90$ gün, kadınlar ortalama 1,76 $\pm 0,85$ gün kaldığ 1 tespit edilip istatistiksel olarak anlamlı fark bulunmuştur $(\mathrm{p}=0.004)$.

Psikiyatrik bozukluklar ve alınan ilaç adedi karşılaştırıldığında ise depresyon tanısı alan hastaların daha fazla sayıda ilaç aldığı görüldü $(p=0,017)$. Yaşa göre alınan ilaç çeşitlerine bakıldığında yirmi yaş ve altındaki hastalar daha çok parasetamolle $(\% 43.85)$, yirmi yaş üstü hastalar ise daha çok antidepresanlarla $(\% 45,71)$ intihar girişiminde bulunmuştu. İntihar düşüncesinin devam ettiği hasta grubunu, daha çok depresyon ve anksiyete tanısı alan hastalar oluşturmaktaydı.

\section{TARTIŞMA}

Zehirlenmeler multidisipliner yaklaşım gerektirmektedir. Hastanemiz Acil Servisine zehirlenme nedeniyle başvuran olguların anamnezleri alındıktan sonra birincil değerlendirmede genel olarak bütün vakaların bilinç durumu, solunum ve dolaşımı değerlendirilmektedir. Hastalar ilaç alımı sonrasında 2-4 saat içerisinde başvurduysa ve başvuru öncesinde başka bir sağlık kuruluşunda gastrik dekontaminasyon uygulanmadiysa mide lavajı ve aktif kömür uygulanmaktadır. Hastalar mevcut klinik durumlarına göre Dahili Yoğun Bakım Ünitesinde ya da Dahiliye Kliniğinde yatırılarak, Zehir Danışma Merkezinin önerileri doğrultusunda takip ve tedavi edilmektedir.

Acil servislere başvuran tüm zehirlenme vakalarının \%95'ini intihar girişimleri oluşturur (5). Staikowsky ve arkadaşları intihar girişimi sonucu ilaç zehirlenmesi olarak inceledikleri 722 olgunun yaklaşık 2/3'sinin kadın ve ortalama yaş grubunun da 33,3 olduğunu bildirmişlerdir (10). Diğer çalışmalarda da intihar girişim yaşı daha çok 30 yaş altı olarak bildirilmiştir $(7,8,11)$. Bu çalışmada da ortalama yaş $25,04 \pm 9,61$ olup \%75,6'sı kadın olduğu tespit edilmiş olup literatürle paralellik göstermektedir.

İlaç zehirlenmelerinde en sık kullanılan ajan antidepresanlardır. Depresif hastalarda intihar girişimi yüksektir ve genelde bu hastaların kendi ilaçlarıyla intihar girişiminde bulundukları tespit edilmiştir. $\mathrm{Bu}$ konuda yapılan araştırmalar intihar girişimlerinin \% 50'sini oluşturan olguların daha önceden psikiyatrik sorunları olan hastalar olduğunu göstermiştir $(12,13)$. Bu çalışmada da hastaların \%28,3'ü antidepresan ajanlarla ve hastaların ikisi dışında hepsi kendi kullandığ ilaçlarla intihar girişiminde bulunmuştur. Yapılan psikiyatrik değerlendirmeler sonucu \%49,6's1 depresif bulunmuş ve daha öncesinden de \%38,1'inin antidepresan ajan kullanan hastalar olduğu görülmüştür.

Zehirlenme vakalarında ilaç alımından sonraki acile başvuru süreleri ile ilgili verilere bakıldığında, ülkemizde yapılan çalışmalarda ilk 2 saatte başvuru oranları \%45,2 (14) ve \%39,3 (15) olarak bildirilmiștir. Bu çalıșmada ise olguların $\% 37$ si ilk 1 saatte, $\% 58,3$ 'ü ilk 2 saatte acil servise başvurmuştur.

Zehirlenme olgularında, yoğun bakımda takip edilme oranları $\mathrm{Ok}$ ve arkadaşlarının çalışmasında \% 26 (15), Yeşil ve arkadaşlarının 
çalışmasında ise \%13,6 (16) olarak bildirilmiştir. $\mathrm{Bu}$ çalışmada ise bu oran \%26 olarak bulundu. İleri hava yolu girişimi ya da ileri kardiyak yaşam desteği gerektiren hastamız olmamasına rağmen Yoğun Bakım Ünitesinde takip edilme oranları yüksektir. $\mathrm{Bu}$ durum, solunum veya kardiyak depresyon oluşturabilecek ilaç alan vakaları daha yakından takip edebilmek amacıyla herhangi bir komplikasyon gelişmeden, yoğun bakım ünitesine alınmasından kaynaklanmaktadır.

Zehirlenme olgularının hastanede kalış süresi Kurt ve arkadaşlarının çalışmasında 3.56 gün (17), Ersoy ve arkadaşlarının çalışmasında ise ortalama 3.0 \pm 3.6 (18) gün olarak tespit edilmiştir. Bizim çalışmamızda hastanede yatış süresi ortalama 1,88 gün olup literatüre göre daha düşük bulunmuştur. Bunun nedeni, hastaların acil servise başvuru sürelerinin literatürde bildirilenlere göre daha kısa olması, hastaların hiçbirinde komplikasyon gelişmemesi ve ileri havayolu açıklığına gerek duyan vakanın olmaması olabilir.

İlaç zehirlenmelerinde literatürde bildirilen mortalite oranlarına bakıldığında Yağan ve arkadaşlarının çalışmasında \% 0.31 (19) ve Akköse ve arkadaşları ise \% 10 (20) olarak bildirilmiştir. Bizim çalışmamızda yine literatürle uyumsuz olarak ölümle sonuçlanan vakamız yoktur. Bunu ilaç alımından sonra acil servisimize başvuru süresinin kısa olmasına bağlamaktayız. Sonuç olarak intihar amaçlı ilaç alımlarında genç yaş grubu ve kadınlar risk altındaki gruptur. Özellikle depressif psikiyatrik bozukluğu olan kişilerde intihar girişimi daha sık görülmektedir. Aynı zamanda ilaç alımlarından sonra, kısa sürede hastaneye başvuru hastanede kalış süresini ve mortaliteyi azaltmaktadır.

\section{KAYNAKLAR}

1. Pınar A, Fowler J. Acute poisoning in İzmir, Turkey. A pilot epidemiologic study. J Toxicol Clin Toxicol 1993; 31(4):593-601.

2. Gunnell D, Eddleston M. Suicide by intentional ingestion of pesticides: a continuing tragedy in developing countries. Int J Epidemiol 2003; 32(6): 902-9.http://dx.doi.org/10.1093/ije/dyg307.

3. Göksu S, Yıldırım C, Kocaoğlu H, Tutak A, Öner U. Characteristics of acute adult poisoning in Gaziantep, Turkey. J Toxicol Clin Toxicol 2002; 40(7): 833-7.

4. Murphy GE. Why women are less likely than men, to commit suicide. Compr Pschiatry 1998:39(4):165-75.

5. Fuller GN, Rea AJ, Payne JF, Lant AF. Parasuicide in central London 1984-1988. J R Soc Med 1989; 82(11): 653-6.

6. Kayhan Z. Klinik Anestezi. 2. Basım. İstanbul: Logos Yayıncılık 1997; 754-8.

7. Hawton K. Assessment of suicide risk. Br J Psychiatry 1987;150:145-53.

8. Appleby L. Suicide in psychiatric patients: risk and prevention. Br J Psychiatry 1992;161:749-58.

9. Oquendo MA, Malone KM, et al. Inadequacy of antidepressant treatment for patients with major depression who are at risk for suicidal behavior, Am J Psychiatry. 1999;156(2):190-4.

10. Staikowsky F, Uzan D, Grillon N, Pevirieri F, Hafi A, Michard F. Voluntary drug poisoning cases admitted to an emergency care unit. Presse Med 1995; 24(28): 1296-300.

11. Güz H, Doğanay Z, Ozkan A. Farmakolojik ajanlarla olan intihar girişimlerinin değerlendirilmesi. O.M.Ü Tip Dergisi 2001;18(4):295-300.

12. Beskow J. Depression and suicide. Pharmacopsychiatry 1990; 23:3-8. http://dx.doi.org/10.1055/s-20071014522.

13. Cheng AT. Mental illness and suicide. A case-control study in East Taiwan. Arch Gen Psychiatry 1995;52:594-603 http://dx.doi.org/10.1001/archpsyc.1995.03950190076011.

14. Karcıoğlu Ö, Demirel Y, Esener Z ve ark. Acil Serviste ilaç ile Zehirlenmeler: Bir Yıllık Olgu Serisi. Acil Tip Dergisi 2002;2(2):26-33.

15. Ok G, Erbüyün K, Mirzai T, Vatansever D, Tok D. Acil servise başvuran zehirlenme olgularının retrospektif olarak incelenmesi. Toksikoloji Dergisi 2006; 4(3-4): 5-9.

16. Yeşil O, Akoğlu H, Onur Ö ve ark. Acil servise başvuran zehirlenme olgularının geriye dönük analizi. Marmara Medical Journal 2008;21(1);26-32.

17. Kurt I, Erpek AG, Kurt MN, et al. Epidemiology of adult poisoning at the Adnan Menderes University. ADU Tip Fakultesi Dergisi 2004;5(1):37-40.

18. Ersoy A, Kara D, Cangir CC, Erdoğan E, Ali A, Büyükyıldırım A. Yoğun Bakımda İntoksikasyon Olgularının Değerlendirilmesi. Okmeydanı Tıp Dergisi 2013;29(2):72-5.

19. Yağan O, Akan B, Erdem D, et al. The retrospective analysis of the acute poisoning cases applying to the emergency unit in one year. Şişli Etfal Hastanesi Tıp Bulteni 2009; 43(1):60-4.

20. Akkose S, Fedakar R, Bulut M, et al. Epidemiology of poisoning in adults: a 5 year study. Acil Tip Dergisi 2003; 3(1): 8-10. 